\title{
Effect of a conditional cash transfer programme on childhood @ Q mortality: a nationwide analysis of Brazilian municipalities
}

Davide Rasella, Rosana Aquino, Carlos A T Santos, Rômulo Paes-Sousa, Mauricio L Barreto

\begin{abstract}
Summary
Background In the past 15 years, Brazil has undergone notable social and public health changes, including a large reduction in child mortality. The Bolsa Familia Programme (BFP) is a widespread conditional cash transfer programme, launched in 2003, which transfers cash to poor households (maximum income US\$70 per person a month) when they comply with conditions related to health and education. Transfers range from \$18 to \$175 per month, depending on the income and composition of the family. We aimed to assess the effect of the BFP on deaths of children younger than 5 years (under-5), overall and resulting from specific causes associated with poverty: malnutrition, diarrhoea, and lower respiratory infections.
\end{abstract}

Methods The study had a mixed ecological design. It covered the period from 2004-09 and included 2853 (of 5565) municipalities with death and livebirth statistics of adequate quality. We used government sources to calculate allcause under-5 mortality rates and under-5 mortality rates for selected causes. BFP coverage was classified as low $(0 \cdot 0-17 \cdot 1 \%)$, intermediate $(17 \cdot 2-32 \cdot 0 \%)$, high $(>32 \cdot 0 \%)$, or consolidated $(>32 \cdot 0 \%$ and target population coverage $\geq 100 \%$ for at least 4 years). We did multivariable regression analyses of panel data with fixed-effects negative binomial models, adjusted for relevant social and economic covariates, and for the effect of the largest primary health-care scheme in the country (Family Health Programme).

Findings Under-5 mortality rate, overall and resulting from poverty-related causes, decreased as BFP coverage increased. The rate ratios (RR) for the effect of the BFP on overall under-5 mortality rate were 0 - 94 (95\% CI 0 - 92-0 - 96) for intermediate coverage, $0.88(0.85-0.91)$ for high coverage, and $0.83(0.79-0.88)$ for consolidated coverage. The effect of consolidated BFP coverage was highest on under-5 mortality resulting from malnutrition (RR $0.35 ; 95 \% \mathrm{CI}$ $0 \cdot 24-0 \cdot 50)$ and diarrhoea $(0 \cdot 47 ; 0 \cdot 37-0 \cdot 61)$.

Interpretation A conditional cash transfer programme can greatly contribute to a decrease in childhood mortality overall, and in particular for deaths attributable to poverty-related causes such as malnutrition and diarrhoea, in a large middle-income country such as Brazil.

Funding National Institutes of Science and Technology Programme, Ministry of Science and Technology, and Council for Scientific and Technological Development Programme (CNPq), Brazil.

\section{Introduction}

Conditional cash transfer programmes are interventions that transfer cash from governments to poor households with the requirement that parents comply with specific conditions (or conditionalities), usually focused on health and education for their children. ${ }^{1}$ The transfer of benefits aims to promptly alleviate poverty and the conditions encourage use of existing health and education services. The first conditional cash transfer programmes were implemented in the late 1990s in Mexico and Brazil, spreading rapidly to various countries worldwide, becoming an important strategy for alleviation of poverty and reduction of inequalities in low-income and middle-income countries., ${ }^{1,2}$

In Brazil, the Bolsa Familia programme (Family Allowance, BFP), launched in 2003, merged four preexisting national social programmes into one unique expanded programme. ${ }^{3}$ The BFP is the world's largest conditional cash transfer programme, and its coverage has expanded greatly in the past 10 years. It reached all 5565 Brazilian municipalities and enrolled 13.4 million families in 2011, with a total budget of US $\$ 11.2$ billion. ${ }^{4}$ The cash transfers are intended for extremely poor families (with an income of less than \$35 per person per month) and for other families deemed poor (with an income of between $\$ 35$ and $\$ 70$ per person per month) when they include children up to 17 years of age or pregnant or lactating women. ${ }^{5}$ Poor families receive about $\$ 18$ for each pregnant woman, child, or adolescent up to 17 years of age (with an upper limit for each category), whereas extremely poor families, besides receiving the same benefits, receive an additional contribution of $\$ 35$ irrespective of the composition of the family. According to these criteria, benefits can range from $\$ 18$ to a maximum of $\$ 175$ per month. The mother (when present) must receive the monthly payment on behalf of the whole family.

A family enrolled in the BFP has to comply with specific education and health-related conditions. To meet the health conditions children younger than 7 years must be vaccinated according to the Brazilian immunisation programme schedule and must comply with health check-ups and growth monitoring according to Ministry
Lancet 2013; 382: 57-64 Published Online May 15, 2013 http://dx.doi.org/10.1016/ S0140-6736(13)60715-1

See Comment page 7

Instituto de Saúde Coletiva Federal University of Bahia, Salvador, Bahia, Brazil (D Rasella PhD, R Aquino MD, CAT Santos PhD, Prof M L Barreto MD); Department of Exact Sciences, State University of Feira de Santana, Feira de Santana, Bahia, Brazil (C A T Santos); Institute of Development Studies, University of Sussex, Brighton, UK

(R Paes-Sousa MD); and Ciência, Tecnologia e Inovação em Saúde, INCT-CITECS, Salvador, Bahia, Brazil (Prof M L Barreto)

Correspondence to: Prof Mauricio Barreto, Instituto de Saúde Coletiva, Universidade Federal de Bahia, Canela, 41110-040, Salvador, Bahia, Brazil mauricio@ufba.br 
of Health guidelines, with a frequency from one to seven times per year, depending on a child's age. Pregnant and lactating women must attend scheduled prenatal and postnatal visits and health and nutritional educational activities. When possible, health-related conditions should be met using the facilities of the main primary health care programme in Brazil, the Programa Saúde da Familia (Family Health Programme, FHP). ${ }^{6}$ The FHP is another large-scale national programme, implemented over the past several years. By 2011, it reached $94 \%$ of municipalities, covering $53 \%$ of the Brazilian population. FHP aims to broaden access to public health services, especially in deprived areas, by offering free, communitybased health care. ${ }^{8}$

Brazil is characterised by large social inequalities, and it has undergone substantial health and social changes in the past 15 years, including a large reduction in deaths of children younger than 5 years (under-5), enabling the country to reach the fourth Millennium Development Goal. ${ }^{9,10}$ FHP is one of the components that has brought about the substantial decrease in under-5 mortality. ${ }^{11,12}$ We postulate that the BFP should reduce childhood mortality by acting on social determinants of health and by stimulating health care through its conditions. Previous studies have reported the effectiveness of BFP in reducing child malnutrition, ${ }^{13,14}$ but no studies have addressed its effect on childhood morbidity or mortality. Therefore, the objective of the present study was to assess the effect of the BFP on under-5 mortality rates in Brazilian municipalities, focussing on causes of mortality associated with poverty (such as malnutrition, diarrhoea, and lower respiratory infections) and on some of the potential intermediate mechanisms (such as vaccination, prenatal care, and admission to hospital).

\section{Methods \\ Study design}

This study has a mixed ecological design, combining an ecological multiple-group design with a time-trend design. The municipality is the unit of analysis. We created a longitudinal dataset from several databases for the years 2004-09. From the 5565 Brazilian municipalities, we selected a subset that had adequate vital statistics (death and livebirth registration) during the first years of the period under study (2004-06; we assumed constant adequacy for the remaining years because of improvements in collection of vital information)..$^{15}$ We assessed adequacy of mortality information according to a validated multidimensional criterion, ${ }^{16}$ which took into account the value of the age-standardised mortality rate of the municipality, the ratio between registered and estimated birth rates, the percentage of poorly defined deaths, and the mean deviation of the previous two parameters for 2004-06. We obtained mortality rates by direct calculation - the number of deaths of children younger than 5 years per 1000 livebirths. Groups of selected causes of mortality and admission to hospital were created by aggregation of categories from the International Classification of Diseases, 10th revision: ${ }^{17}$ diarrhoeal diseases (A00, A01, A03, A04, A06-09), malnutrition (E40-46), lower respiratory infections (J10-18, J20-22), and external causes (V01-98). Mortality attributed to external causes (which includes transport accidents, homicides, and accidental injuries) was included as a control because no effect from either of the programmes was expected. Rates of under-5 admission to hospital were also obtained by direct calculation. A vaccination coverage index for children younger than 1 year was created with areas dichotomised into those where coverage of three main vaccines (measles, oral polio, and diphtheria-pertussis-tetanus [DPT]) was higher than $95 \%$ and those with lower coverage.

For the BFP, it is possible to concieve of two indicators of coverage. The first is coverage of the target population, calculated as the number of families enrolled in the BFP in a municipality divided by the number of eligible families (according to BFP criteria) in the same municipality. ${ }^{4}$ The second is coverage of the total population, calculated as the number of individuals enrolled in the BFP (obtained by multiplying the number of beneficiary families by the average family size) divided by the total population of the same municipality. All models have been fitted using these two indicators (appendix p 4). We have also created a coverage indicator combining both indicators. The categories for this BFP coverage indicator were: low (BFP coverage of the total population of the municipality from $0.0 \%$ to $17 \cdot 1 \%)$, intermediate $(17 \cdot 2-32 \cdot 0 \%)$, high $(>32.0 \%)$, and consolidated (BFP coverage of the total population of the municipality $>32.0 \%$ and, at the same time, BFP coverage of the target population $\geq 100 \%$ for at least the previous 4 years). Because of the absence in the scientific literature of previous reference values, the cutoffs used for the categorisation $(17 \cdot 1 \%$ and $32 \cdot 0 \%)$ represented the tertiles of the distribution of BFP coverage of the total population. This indicator, adjusted in the models for the percentage of the target population in the municipality, enabled us to capture the effect of programme duration and the effect of possible programme externalities (ie, positive spillover effects on programme-ineligible inhabitants) in the municipality. ${ }^{2}$ We calculated yearly coverage of the FHP as the ratio of the total number of individuals registered in this programme to the population of the municipality, and it was categorised, for comparability reasons, as in previous studies: $:^{11,12,15}$ without FHP, incipient $(<30.0 \%$ of the population), intermediate $(30 \cdot 0-69.9 \%$ or $\geq 70.0 \%$ for less than the previous 4 years), and consolidated $(\geq 70.0 \%$ for at least the previous 4 years). We selected a set of covariates recognised as determinants of under-5 mortality (all-cause and cause-specific) that were available at the municipality level: monthly income per person, proportion of total municipality population eligible for BFP, prevalence of illiteracy among individuals older than 15 years, percentage of individuals living in households with inadequate sanitation (inadequate water supply, sewers, and garbage collection), total fertility rate, and 
overall rate of admissions to hospital in the municipality. We dichotomised the covariables according to the median value or, when available (as in the case of illiteracy and fertility rates), reference values.

\section{Data sources}

The data used in this study were collected from different information systems. The data sources provided by the Ministry of Health were: mortality information system (under-5 deaths), primary care information system (FHP coverage), information system on livebirths (livebirths), and outpatient information system (admissions to hospital). ${ }^{7}$ We used the Ministry of Social Development databases to calculate BFP coverage, ${ }^{4}$ and we used data from the Brazilian Institute of Geography and Statistics for socioeconomic variables. ${ }^{18}$ Because data for the covariates were obtained from the 2000 and 2010 national census databases, we calculated the annual values from 2004-09 by linear interpolation.

\section{Statistical analyses}

We used conditional negative binomial regression models for panel data - consisting of a relevant number of units of analysis with repeated observations over time-with fixedeffects specification. As explained in detail in the appendix pp 7-9, to verify whether these models were actually removing the individual fixed effects, ${ }^{19}$ we fitted models with different specifications from our dataset, including unconditional negative binomial regression models and conditional Poisson regressions with robust SEs. Conditional fixed-effects negative binomial regression models were shown to be the most appropriate for our analysis. The fixed-effects models, as with any other longitudinal or panel data models, include a second term to control for characteristics of the unit of analysis that are constant during the study period and that have not been included in the model as confounding variables, such as some geographical, historical, or sociocultural aspects of each municipality. We chose the fixed-effects model specification on the basis of the Hausman test and because it is the most appropriate test for assessment of effects in interventions with panel data. ${ }^{20,21}$ We did goodness of fit tests with Akaike information criterion and Bayesian information criterion estimates. ${ }^{19}$ We fitted the same models with continuous or categorised variables (appendix pp 3-4). Whereas continuous variables allow estimation of the average strength of an association along the entire range of values for a variable, categorised variables give a measure of effect that is easier to interpret, comparing defined ranges of values. Moreover, use of different levels of coverage allows verification of the existence of a gradient of effect, related-in our study-to different degrees of implementation of the interventions. ${ }^{11,12,15}$ To assess the association between BFP or FHP coverage and mortality rates, we calculated mortality rate ratios (RRs), both crude and adjusted for covariates, using municipalities with the lowest coverage as the reference category.

To detect any interaction between the BFP and FHP with regard to the reduction of all-cause and cause-specific under- 5 mortality, we created a product term between the BFP and FHP coverage-both dichotomised as consolidated or not consolidated-and fitted models with the same specification as the previous ones but with this term representing the interaction between the two programmes. We did a sensitivity analysis with data from all Brazilian municipalities irrespective of quality of vital information.

\begin{tabular}{|c|c|c|c|c|c|c|c|}
\hline & 2004 & 2005 & 2006 & 2007 & 2008 & 2009 & $\begin{array}{l}\text { Percentage } \\
\text { change } \\
2004-09\end{array}$ \\
\hline \multicolumn{8}{|l|}{ Mortality rate for children younger than 5 years (per 1000 livebirths) } \\
\hline Overall & $21 \cdot 7(14 \cdot 7)$ & $20 \cdot 3(14 \cdot 5)$ & $20 \cdot 1(14 \cdot 6)$ & $19 \cdot 4(14 \cdot 8)$ & $18 \cdot 6(15 \cdot 9)$ & $17 \cdot 5(14 \cdot 7)$ & $-19 \cdot 4 \%$ \\
\hline For diarrhoeal diseases & $0.95(2.93)$ & $0.86(2.54)$ & $0.83(2.67)$ & $0.55(2.02)$ & $0.49(1.96)$ & $0.51(2.46)$ & $-46 \cdot 3 \%$ \\
\hline For malnutrition & $0 \cdot 55(2 \cdot 33)$ & $0.48(2 \cdot 24)$ & $0.36(1 \cdot 70)$ & $0.30(2 \cdot 53)$ & $0 \cdot 20(1 \cdot 26)$ & $0.23(1.54)$ & $-58 \cdot 2 \%$ \\
\hline For lower respiratory infections & $1.15(3 \cdot 30)$ & $0.96(2.72)$ & $1.07(2 \cdot 84)$ & $0.95(2 \cdot 91)$ & $0.98(3.85)$ & $0.84(2 \cdot 84)$ & $-27 \cdot 0 \%$ \\
\hline For external causes & $1.23(3.29)$ & $1.16(3 \cdot 14)$ & $1.06(3.17)$ & $1.16(3 \cdot 80)$ & $1.07(3 \cdot 70)$ & $1.01(3.71)$ & $-17 \cdot 9 \%$ \\
\hline BFP coverage of the municipality population (\%) & $17 \cdot 3 \%(12 \cdot 1)$ & $23 \cdot 0 \%(14 \cdot 0)$ & $28 \cdot 1 \%(17 \cdot 2)$ & $27 \cdot 8 \%(17 \cdot 8)$ & $25 \cdot 2 \%(16 \cdot 7)$ & $28 \cdot 3 \%(17 \cdot 5)$ & $63.6 \%$ \\
\hline FHP coverage of the municipality population (\%) & $62.7 \%(36 \cdot 7)$ & $67.8 \%(34.8)$ & $71 \cdot 0 \%(33.4)$ & $73.9 \%(32.4)$ & $74 \cdot 4 \%(31 \cdot 3)$ & $75.0 \%(30.9)$ & $19.6 \%$ \\
\hline Income per person (monthly, in BR\$) & $310(126)$ & $339(135)$ & $368(145)$ & $396(154)$ & $425(164)$ & $454(147)$ & $46 \cdot 5 \%$ \\
\hline Proportion of BFP eligible population in the municipality & $27 \cdot 9 \%(16 \cdot 5)$ & $27 \cdot 8 \%(16 \cdot 7)$ & $27 \cdot 8 \%(16 \cdot 8)$ & $27 \cdot 7 \%(16 \cdot 9)$ & $26 \cdot 5 \%(15 \cdot 5)$ & $26 \cdot 3 \%(15 \cdot 5)$ & $-5 \cdot 7 \%$ \\
\hline Proportion of individuals living in households with inadequate sanitation & $22 \cdot 9 \%(16 \cdot 4)$ & $21 \cdot 7 \%(15 \cdot 8)$ & $20 \cdot 5 \%(15 \cdot 2)$ & $19 \cdot 3 \%(14 \cdot 7)$ & $18 \cdot 2 \%(14 \cdot 3)$ & $17 \cdot 0 \%(13 \cdot 9)$ & $-25 \cdot 8 \%$ \\
\hline Proportion of individuals older than 15 years who are illiterate & $16 \cdot 9 \%(10 \cdot 3)$ & $16 \cdot 4 \%(10 \cdot 0)$ & $15 \cdot 9 \%(9 \cdot 8)$ & $15 \cdot 4 \%(9 \cdot 6)$ & $14 \cdot 9 \%(9 \cdot 3)$ & $14 \cdot 4 \%(9 \cdot 1)$ & $-14 \cdot 8 \%$ \\
\hline Total fertility rate & $2 \cdot 31(0 \cdot 62)$ & $2 \cdot 27(0.63)$ & $2.20(0.64)$ & $2 \cdot 14(0.65)$ & $2.07(0.65)$ & $2.01(0.67)$ & $-13 \cdot 0 \%$ \\
\hline Rate of admissions to hospital (per 100 inhabitants) & $4 \cdot 88(4 \cdot 47)$ & $4 \cdot 69(4 \cdot 34)$ & $4 \cdot 58(4 \cdot 39)$ & $4 \cdot 46(4 \cdot 11)$ & $4.02(4.11)$ & $4.04(4 \cdot 23)$ & $-17 \cdot 2 \%$ \\
\hline \multicolumn{8}{|c|}{$\begin{array}{l}\text { Data are mean (SD). Causes of death were defined according to the International Classification of Diseases, } 10 \text { th revision:17 diarrhoeal diseases (A00, A01, A03, A04, A06-09), malnutrition (E40-46), lower } \\
\text { respiratory infections (J10-18, J20-22), and external causes (V01-98). Rate of admission to hospital was calculated as the number of admissions to hospital for all ages and all causes of one municipality divided } \\
\text { by the total population of the same municipality and multiplied by } 100 \text {. BFP=Bolsa Familia Programme. FHP=Family Health Programme. }\end{array}$} \\
\hline
\end{tabular}




\begin{tabular}{|c|c|c|c|c|c|}
\hline & \multicolumn{2}{|l|}{ BFP models } & \multicolumn{2}{|l|}{ FHP models } & \multirow[t]{2}{*}{ FHP and BFP (adjusted) } \\
\hline & Crude & Adjusted & Crude & Adjusted & \\
\hline \multicolumn{6}{|l|}{ BFP population coverage } \\
\hline Low $(0 \cdot 0-17 \cdot 1 \%)$ & 1.00 & 1.00 & .. & .. & 1.00 \\
\hline Intermediate (17.2-32.0\%) & $0.91(0.90-0.93)$ & $0.93(0.91-0.95)$ & .. & .. & $0.94(0.92-0.96)$ \\
\hline High $(>32 \cdot 0 \%)$ & $0.82(0.80-0.85)$ & $0.86(0.83-0.89)$ & .. & .. & $0.88(0.85-0.91)$ \\
\hline Consolidated ( $>32.0 \%$ and TPC $\geq 100 \%$ for at least 4 years) & $0.76(0.72-0.80)$ & $0.81(0.76-0.85)$ & .. & .. & $0.83(0.79-0.88)$ \\
\hline \multicolumn{6}{|l|}{ FHP municipality population coverage } \\
\hline No FHP $(0 \cdot 0 \%)$ & .. & .. & 1.00 & $1 \cdot 00$ & 1.00 \\
\hline Incipient $(<30 \%)$ & .. & .. & $0.97(0.92-1.02)$ & $0.98(0.94-1.03)$ & $0.99(0.94-1.04)$ \\
\hline Intermediate ( $\geq 30 \%)$ & .. & .. & $0.89(0.85-0.93)$ & $0.91(0.87-0.96)$ & $0.93(0.88-0.97)$ \\
\hline Consolidated ( $\geq 70 \%$ and implemented for at least 4 years) & .. & .. & $0.81(0.77-0.86)$ & $0.85(0.80-0.90)$ & $0.88(0.83-0.93)$ \\
\hline Income per person (monthly, $>\mathrm{BR} \$ 380)^{*}$ & .. & $0.94(0.92-0.97)$ & .. & $0.93(0.91-0.96)$ & $0.95(0.92-0.97)$ \\
\hline Proportion of municipality population eligible for BFP* $>22 \cdot 4 \%$ & .. & $1.07(1.02-1 \cdot 11)$ & .. & $1 \cdot 10(1 \cdot 06-1 \cdot 15)$ & $1.07(1.03-1 \cdot 12)$ \\
\hline $\begin{array}{l}\text { Proportion of individuals living in households with inadequate } \\
\text { sanitation* }<16.7 \%\end{array}$ & .. & $1.10(1.05-1.15)$ & .. & $1 \cdot 11(1.06-1 \cdot 16)$ & $1.10(1.05-1.15)$ \\
\hline $\begin{array}{l}\text { Proportion of individuals older than } 15 \text { years who are illiterate } \dagger \\
>11.1 \%\end{array}$ & .. & $1.04(1.00-1.09)$ & .. & $1 \cdot 05(1 \cdot 01-1 \cdot 10)$ & $1.04(1.00-1.08)$ \\
\hline Total fertility rate $\dagger>2 \cdot 32$ & .. & $1.08(1.04-1.11)$ & .. & $1.08(1.05-1.12)$ & $1.07(1.03-1.10)$ \\
\hline Rate of admission to hospital (per 100 inhabitants) ${ }^{*}>4 \cdot 27$ & .. & $1.02(0.99-1.04)$ & .. & $1.02(0.99-1.04)$ & $1.01(0.99-1.04)$ \\
\hline Number of observations & 17118 & 17118 & 17118 & 17118 & 17118 \\
\hline Number of municipalities & 2853 & 2853 & 2853 & 2853 & 2853 \\
\hline
\end{tabular}

We used Stata (version 12.0) for database processing and analysis.

\section{Role of the funding source}

The sponsor of the study had no role in study design, data collection, data analysis, data interpretation, or writing of the report. The corresponding author had full access to all the data in the study and had final responsibility for the decision to submit for publication.

\section{Results}

The criteria for adequate death and livebirth registration were met by 2906 municipalities. Of these, 2853 (51\% of all Brazilian municipalities) had data available for all covariates and were included in our analysis. From 2004-09, the mean under-5 mortality rate decreased by $19.4 \%$ in the studied municipalities, and among the selected causes, the greatest decrease was associated with malnutrition (58.2\%; table 1$)$. Under-5 mortality associated with external causes decreased by $17.9 \%$. Mean BFP coverage in the municipalities exhibited some yearly variation during the study period, reaching a peak in 2009 with $28 \cdot 3 \%$ coverage. Mean FHP coverage in the municipalities continually increased, reaching $75.0 \%$ in 2009. Socioeconomic conditions improved during the study period, with the mean monthly income per person increasing by $46.5 \%$ and the percentage of individuals living in households with inadequate sanitation decreasing by $25 \cdot 8 \%$ (table 1 ).
Table 2 shows the crude and adjusted associations of under-5 mortality rate with BFP and FHP municipal coverage levels. In the analysis, both measures of BFP and FHP coverage exhibited a significant dose-response association with decreasing under-5 mortality rate, even after the adjustment for socioeconomic and demographic covariates. We indentified much the same results in models for which all the variables were imputed as continuous (appendix p 3). Table 3 shows the effect of BFP and FHP municipal coverage on selected causes of under-5 mortality. Both interventions had an effect on all selected causes except for external causes, which were used as a control. The strongest effect of the BFP was on under-5 mortality resulting from malnutrition, whereas the FHP was associated with the greatest reduction in diarrhoeal diseases and lower respiratory infections (table 3).

As shown in table 4, in multivariable models that controlled for FHP coverage and relevant covariates, the increase in BFP coverage increased vaccination coverage for measles, polio, and DPT, reduced the number of pregnant women who delivered without receiving any prenatal care, and reduced rates of under- 5 admissions to hospital in a manner much the same as for the reduction in mortality rates, having the strongest effect on malnutrition and no effect on external causes.

When we included an interaction term between BFP and FHP in the models, this term was negatively associated with all mortality rates, both overall or for specific causes, but the association was significant only 


\begin{tabular}{|c|c|c|c|c|c|c|c|}
\hline & & & Diarrhoeal diseases & Malnutrition & \multicolumn{2}{|c|}{ Lower respiratory infections } & External causes \\
\hline \multicolumn{8}{|c|}{ BFP municipality population coverage } \\
\hline \multicolumn{3}{|l|}{ Low $(0 \cdot 0-17 \cdot 1 \%)$} & 1.00 & 1.00 & \multicolumn{2}{|l|}{1.00} & 1.00 \\
\hline \multicolumn{3}{|c|}{ Intermediate (17.2-32.0\%) } & $0.83(0.74-0.92)$ & $0.66(0.57-0.77)$ & \multicolumn{2}{|c|}{$0.96(0.88-1.05)$} & $1.03(0.95-1.13)$ \\
\hline \multicolumn{3}{|c|}{$\operatorname{High}(>32.0 \%)$} & $0.68(0.59-0.80)$ & $0.54(0.44-0.67)$ & \multicolumn{2}{|c|}{$0.94(0.82-1.07)$} & $0.92(0.79-1.06)$ \\
\hline \multicolumn{3}{|c|}{ Consolidated ( $>32.0 \%$ and TPC $\geq 100$ for at least 4 years) } & $0.47(0.37-0.61)$ & $0.35(0.24-0.50)$ & \multicolumn{2}{|c|}{$0.80(0.64-0.99)$} & $0.92(0.72-1.16)$ \\
\hline \multicolumn{8}{|c|}{ FHP municipality population coverage } \\
\hline \multicolumn{3}{|l|}{ No FHP $(0 \cdot 0 \%)$} & 1.00 & 1.00 & \multicolumn{2}{|l|}{1.00} & 1.00 \\
\hline \multicolumn{3}{|l|}{ Incipient (<30\%) } & $0.90(0.67-1.17)$ & $0.88(0.60-1.29)$ & \multicolumn{2}{|c|}{$0.83(0.68-1.00)$} & $0.95(0.79-1.14)$ \\
\hline \multicolumn{3}{|c|}{ Intermediate ( $\geq 30 \%)$} & $0.71(0.54-0.93)$ & $0.72(0.49-1.07)$ & \multicolumn{2}{|c|}{$0.71(0.58-0.86)$} & $0.87(0.72-1.05)$ \\
\hline \multicolumn{3}{|c|}{ Consolidate ( $\geq 70 \%$ and implemented for at least 4 years) } & $0.53(0.39-0.71)$ & $0.59(0.38-0.91)$ & $0.70(0.56$ & $6-0 \cdot 87)$ & $0.87(0.70-1.08)$ \\
\hline Number of observati & & & 7356 & 5124 & 9894 & & 10776 \\
\hline Number of municipa & & & 1226 & 854 & 1649 & & 1796 \\
\hline $\begin{array}{l}\text { Data are rate ratio }(95 \% \\
\text { sanitation, proportion o }\end{array}$ & $\begin{array}{l}\text { unless otherwise specified } \\
\text { dividuals older than } 15 \text { yea }\end{array}$ & $\begin{array}{l}\text { Models adjusted for inco } \\
\text { ars who are illiterate, total }\end{array}$ & $\begin{array}{l}\text { ome per person, proportion } \\
\text { fertility rate, and rate of adr }\end{array}$ & $\begin{array}{l}\text { of municipality population } \\
\text { missions to hospital. }\end{array}$ & eligible for BFP, proportior & n of individuals living in $\mathrm{h}$ & households with inadequate \\
\hline $\begin{array}{l}\text { Table 3: Fixed-effect I } \\
\text { rates for some releva }\end{array}$ & $\begin{array}{l}\text { gative binomial models } \\
\text { groups of causes }\end{array}$ & for adjusted associatio & ons between Bolsa Famili & lia Programme (BFP) and & d Family Health Progran & mme (FHP) coverage a & and under-5 mortality \\
\hline & $\begin{array}{l}\text { Measles, polio, and } \\
\text { DPT vaccine } \\
\text { coverage over } 95 \% \\
\text { among children } \\
\text { younger than } 1 \text { year } \\
\mathrm{OR}^{*}(95 \% \mathrm{Cl})\end{array}$ & $\begin{array}{l}\text { Proportion of } \\
\text { pregnant women } \\
\text { with no prenatal } \\
\text { visits at the moment } \\
\text { of delivery RR } \dagger \\
(95 \% \mathrm{Cl})\end{array}$ & $\begin{array}{l}\text { Under- } 5 \text { rate of } \\
\text { admission to } \\
\text { hospital RR } \ddagger \\
(95 \% \mathrm{Cl})\end{array}$ & $\begin{array}{l}\text { Under-5 rate of } \\
\text { admission to } \\
\text { hospital for } \\
\text { diarrhoeal diseases } \\
\mathrm{RR} \neq(95 \% \mathrm{Cl})\end{array}$ & $\begin{array}{l}\text { Under-5 rate of } \\
\text { admission to } \\
\text { hospital for } \\
\text { malnutrition RR } \ddagger \\
(95 \% \mathrm{Cl})\end{array}$ & $\begin{array}{l}\text { Under- } 5 \text { rate of } \\
\text { admission to } \\
\text { hospital for lower } \\
\text { respiratory } \\
\text { infections RR } \neq \\
(95 \% \mathrm{Cl})\end{array}$ & $\begin{array}{l}\text { Under-5 rate of } \\
\text { admission to } \\
\text { hospital for external } \\
\text { causes } \mathrm{RR} \ddagger(95 \% \mathrm{Cl})\end{array}$ \\
\hline BFP municipality pop & lation coverage & & & & & & \\
\hline Low $(0 \cdot 0-17 \cdot 1 \%)$ & 1.00 & 1.00 & 1.00 & 1.00 & 1.00 & 1.00 & 1.00 \\
\hline $\begin{array}{l}\text { Intermediate } \\
(17 \cdot 2-32 \cdot 0 \%)\end{array}$ & $1.47(1.29-1.68)$ & $0.85(0.83-0.87)$ & $0.96(0.95-0.97)$ & $0.86(0.84-0.87)$ & $0.82(0.76-0.87)$ & $0.95(0.93-0.97)$ & $1 \cdot 30(0.85-1.99)$ \\
\hline High $(>32.0 \%)$ & $1.98(1.48-2 \cdot 43)$ & $0.66(0.63-0.69)$ & $0.92(0.90-0.94)$ & $0.80(0.77-0.83)$ & $0.68(0.62-0.75)$ & $0.88(0.85-0.91)$ & $1.19(0 \cdot 45-3 \cdot 18)$ \\
\hline $\begin{array}{l}\text { Consolidated } \\
(>32.0 \% \text { and TPC } \\
\geq 100 \text { for at least } \\
4 \text { years })\end{array}$ & $2.05(1.53-2.76)$ & $0.53(0.48-0.57)$ & $0.84(0.81-0.86)$ & $0.61(0.57-0.65)$ & $0.53(0.44-0.63)$ & $0.88(0.83-0.93)$ & $0.62(0.10-3.90)$ \\
\hline $\begin{array}{l}\text { Number of } \\
\text { observations }\end{array}$ & 14166 & 15948 & 17118 & 17070 & 12528 & 17118 & 10776 \\
\hline $\begin{array}{l}\text { Number of } \\
\text { municipalities }\end{array}$ & 2361 & 2658 & 2853 & 2845 & 2088 & 2853 & 1796 \\
\hline $\begin{array}{l}\mathrm{OR}=\text { odds ratio. } \mathrm{RR}=\text { rate } \\
+ \text { Estimated by negative } \\
\text { population eligible for }\end{array}$ & $\begin{array}{l}\text { tio. DTP=diphtheria, tetanu } \\
\text { nomial regression models a } \\
\text {, proportion of individuals }\end{array}$ & $\begin{array}{l}\text { us, pertussis. TPC=target } p \\
\text { adjusted for FHP coverage. } \\
\text { living in households with }\end{array}$ & $\begin{array}{l}\text { opulation coverage. } \mathrm{FHP}=\mathrm{F} \\
\text {. } \neq \text { Estimated by negative bi } \\
\text { inadequate sanitation, prop }\end{array}$ & $\begin{array}{l}\text { Family Health Programme. " } \\
\text { inomial regression models a } \\
\text { sportion of individuals older }\end{array}$ & $\begin{array}{l}\text { *Estimated by logistic regr } \\
\text { adjusted for FHP coverage } \\
r \text { than } 15 \text { years who are illit }\end{array}$ & $\begin{array}{l}\text { ression models adjusted } \\
\text { income per person, pro } \\
\text { terate, and total fertility r }\end{array}$ & $\begin{array}{l}\mathrm{d} \text { for FHP coverage. } \\
\text { oportion of municipality } \\
\text { y rate. }\end{array}$ \\
\hline
\end{tabular}

in the models for overall under-5 mortality rate (RR 0.95; 95\% CI 0.91-0.99).

Municipalities with adequate death and livebirth information showed a slightly lower socioeconomic status and a slightly higher BFP coverage than did those with inadequate information (data not shown). A sensitivity test, done by fitting the models with data from all Brazilian municipalities, showed slightly lower, but significant, effects of the two interventions: the effect on overall under- 5 mortality of consolidated BFP coverage was RR 0.83 (95\% CI $0.78-0.87)$ and of consolidated FHP coverage was $0 \cdot 91(0 \cdot 87-0 \cdot 94)$, while for under-5 diarrhoea mortality was $0.52(0.41-0.66)$ for consolidated BFP and $0.65(0.54-0.79)$ for consolidated
FHP. We identified much the same results for malnutrition and respiratory infection (data not shown).

\section{Discussion}

The results of our study show that BFP had a significant role in reduction of under-5 mortality, overall and from poverty-related causes such as malnutrition and diarrhoea, in Brazilian municipalities from 2004-09. The effect was maintained even after the adjustment for socioeconomic covariables and FHP. The increase in BFP duration and in coverage of both the total and target populations strengthens the effect of the programme. The effect of the BFP was stronger when, with high municipality population coverage, full coverage of the 
target population of poor families was maintained for 4 years or more. With regard to factors involved in the causal chain of mortality reduction, the BFP substantially reduced rates of under-5 admission to hospital and increased vaccination coverage and prenatal visits.

Because the BFP and FHP have been implemented on a large scale over the same period in the same areas in Brazil, we had a unique opportunity to explore their joint effects. The effectiveness of the FHP in reduction of overall infant and child mortality, reducing under- 5 mortality resulting from diarrhoea and lower respiratory infections, increasing vaccination coverage, and reducing admissions to hospital has already been shown. ${ }^{11,12,22}$ However, none of these studies included the effect of the BFP in their analyses.

Several studies worldwide, summarised in reviews, ${ }^{23-2}$ showed that conditional cash transfer programmes had positive effects on nutritional status and health outcomes of enrolled children, through the increase in the use of preventive services, immunisation coverage, and promotion of healthy behaviours (panel ${ }^{23-25}$ ). Only an econometric study ${ }^{26}$ assessed the effect of a conditional cash transfer programme on infant mortality; the investigators reported that the Mexican conditional cash transfer programme Progresa was able to reduce infant mortality in rural areas. ${ }^{26}$ Our analysis-using a different statistical approach and different mortality outcomes, excluding municipalities

Panel: Research in context

\section{Systematic review}

We searched PubMed, Science Direct, Popline, and Embase with the terms "conditional cash transfer" and "bolsa familia". Searches were not restricted by language or date; the last search was done in June, 2012. We used the reference lists of selected reports to identify other relevant studies.

In a comprehensive systematic review ${ }^{23}$ of the effect of conditional cash transfer programmes on general health outcomes, positive effects of such programmes were identified for child nutritional status and child morbidity. An increased use of general health care and preventive services in children and pregnant women was also reported. ${ }^{24} \mathrm{~A}$ programme theory framework has been proposed to explain the effects of conditional cash transfer on health, ${ }^{25}$ suggesting that the quality of the health services providing conditions is a crucial factor in the effectiveness of such programmes. With regard to the effect of conditional cash transfer programmes on mortality, we identified only one research report, which showed a reduction of infant mortality rates in Mexico, attributed to the effect of the conditional cash transfer programme Progresa, ${ }^{26}$ probably because it increases access to health care for hard-to-reach segments of the population in both rural and urban areas. ${ }^{27}$ However, limitations in the study design and the absence of analysis of some intermediate mechanisms that could explain this mortality reduction-including health-care supplyemphasised the necessity of a broader and more rigorous study of the effect on child mortality of a larger conditional cash transfer programme, such as Bolsa Familia in Brazil.

\section{Interpretation}

The results of our study show that a large-scale conditional cash transfer programme, combined with an effective primary health-care system, can strongly reduce childhood mortality, from poverty-related causes and overall. Mechanisms include effects on social determinants of health and increased use of preventive services in children and pregnant women through programme conditions. with inadequate vital information, using different coverage indicators, and studying the effect of BFP on the intermediate mechanisms of vaccination, prenatal care, and admissions to hospital—showed BFP to have an effect on childhood mortality.

The large magnitude of the effect of the BFP that we identified can be explained by the fact that the number of under-5 deaths from a small number of extremely poor families constitutes a high proportion of all under- 5 deaths in the municipalities. The proportion reaches almost 100\% for poverty-related causes of mortality, such as malnutrition or diarrhoea. A mathematical demonstration and a broader discussion of how this association operates are available in the appendix pp 5-6. Moreover, to understand how the relatively small amount of money provided by the BFP can have an effect on beneficiaries' health, it has to be remembered that this amount is proportional to the economic vulnerability of the families, and that the association between income and health is non-linear: ${ }^{28}$ even a small amount of money, given to extremely poor families, can have an effect on child health, increasing survival.

BFP, like other conditional cash transfer programmes, can affect child survival through different mechanisms (figure), largely centred on income improvement and health conditions: an increased income can increase access to food and other health-related goods, and health-related conditions can improve access to health services. ${ }^{25} \mathrm{~A}$ strong association exists between child undernutrition and child survival-as levels of child undernutrition increase so does the risk of death, especially from diarrhoea and measles. ${ }^{29}$ Research has already shown that poor families enrolled in the BFP increased food expenditures and improved food security in their households..$^{30}$ Overall, Brazil has seen a substantial decrease in child undernutrition during the past decade, particularly among poor families. ${ }^{9}$ The contribution of the BFP to this process has been shown in a few studies, ${ }^{13,14}$ in which children from BFP beneficiary families were more likely to be better nourished than were those from non-beneficiary families. The money allowance from the BFP could likewise reduce the household poverty burden, improving living conditions and removing or reducing barriers to accessing health care, not only for children, but also the rest of the family. ${ }^{31}$

Another important explanation for the effect of the BFP on child survival is associated with the health-related conditions, which include prenatal care, postnatal care, and health and nutrition education activities for mothers, in addition to a regular vaccination schedule and routine check-ups for growth and development for children younger than 7 years. Maternal knowledge and education are some of the strongest determinants of child health, improving nutrition, hygiene practices, and care-seeking for illnesses. ${ }^{31}$ Even when there is conflicting evidence as to whether monitoring of child growth is effective in itself, such monitoring can provide an entry point for preventive and curative health-care services and can reduce the scarcity of contact with the health system, an important 


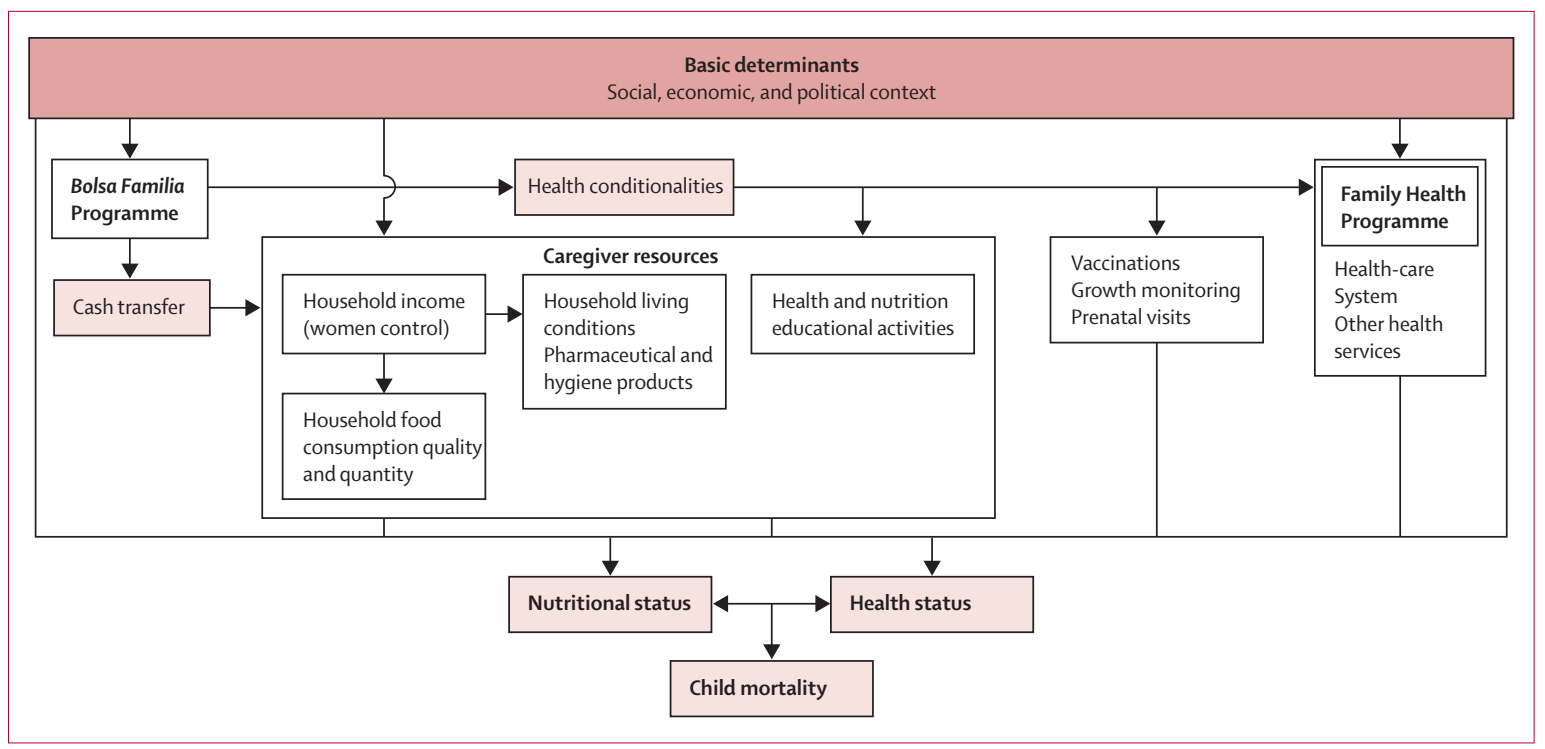

Figure: Mechanisms linking the Bolsa Familia Programme and the Family Health Programme to child nutritional and health outcomes

determinant of child survival in developing countries. ${ }^{32} \mathrm{As}$ shown in our study, the BFP increases prenatal care and vaccination coverage. These interventions are effective for prevention of child mortality. ${ }^{33}$

Even if implementation and coverage of the FHP is not affected by the presence of the BFP, according to the Ministry of Health, the FHP is the strategy of choice to help BFP beneficiaries meet health conditions, and to help them with their health needs. ${ }^{6}$ Unlike the BFP, which has a specific target population, the FHP has the objective of covering all the population of the municipality, offering comprehensive primary health care free of charge. ${ }^{8}$ When BFP beneficiaries are under an FHP catchment area, the FHP team has the formal responsibility to deliver all services linked to the conditions, and community health workers should undertake home visits and actively monitor the completion of conditions. ${ }^{6}$ Compliance with health conditions depends on monitoring and on barriers to accessing services. ${ }^{1,25}$ The FHP increases access to health care, ${ }^{15,34}$ which, according to our results, strengthens the effect of the BFP on FHP beneficiaries compared with BFP beneficiaries who are assisted by traditional health facilities, which are generally more distant and do not undertake community involvement activities and home visits. ${ }^{3}$

We identified a strong effect of the BFP on rates of under-5 admissions to hospital, both overall and for specific causes, which could be explained by two different mechanisms: decreasing the incidence of the diseases by affecting social determinants of health; or by increasing early contacts with the health-care system, thereby reducing the number of severe cases of illness needing admission to hospital. ${ }^{25}$ One of the strengths of our study is that we used a measurement of the intensity of the intervention (the coverage of the BFP) that is specifically linked to the population group that accounts for a large proportion of the outcome (deaths from poverty-related causes), thus reducing the plausibility that the outcomes of interest are coming from the group of people not exposed to the intervention (ie, ecological fallacies).

Another strength of our study was the selection of municipalities with vital information of adequate quality, which improved the study's internal validity, although this selection might limit the generalisability of the results. However, the sensitivity analysis done with all Brazilian municipalities gave much the same effect estimates, suggesting that our findings are robust. In some of the models for selected causes of mortality, the number of observations varied for statistical reasons; municipalities with the same values for the outcome (in this case, 0 deaths) over the entire 6-year period were not included in the model fitting because of a limitation of the fixed-effects model algorithms. ${ }^{19,20}$ However, by comparing the covariate values of the municipalities included in each model with those that were excluded, we identified much the same values, and the estimates of the random effects models (which included all 2853 municipalities in the model fitting) did not affect the sign, significance, or main conclusions reached with the fixed-effects models; the random-effects RR for consolidated BFP coverage was 0.75 for mortality from diarrhoea and 0.61 for mortality from malnutrition. Possible bias introduced by use of crude interpolation rather than more complex estimation techniques was limited by variable categorisation, which can reduce fluctuations that are artificially introduced by the method.

We did not included a variable representing time in the models because the mortality RR, comparing two or more groups of coverage exposed to the same mortality time trend, allowed us to control for secular trends. ${ }^{11,12}$ The introduction of a time variable in the models would have constituted an over-specification problem, as confirmed 
by the sensitivity analyses. The fact that these models were not affected by secular mortality trends was suggested by the estimates of the effect of BFP and FHP on under-5 mortality attributed to external causes: although mortality from external causes was decreasing during the study period, neither programme showed an effect of reduction on mortality from such causes. One limitation of the study was that fixed-effects models can control only for selection bias associated with unmeasured time-constant characteristics of the municipalities. ${ }^{21}$ However, we used a wide set of covariates and showed no effects of either programme on mortality from external causes, suggesting that other possible sources of selection bias or confounding were controlled.

The results of our study provide evidence that a multisectoral approach, combining a large-scale conditional cash transfer programme, with the potential to act on important social health determinants, and effective primary health care, capable of attending basic health demands of the same population and of attending conditions imposed by the conditional cash transfer programme, can substantially reduce childhood mortality from poverty-related causes in a large middleincome country such as Brazil.

\section{Contributors}

MLB, DR, and RA designed the original study in discussion with RP-S. DR collected data. DR and CATS did the data analysis and DR wrote a first draft of the report. All authors contributed to data interpretation and to the review of the report.

\section{Conflicts of interest}

We declare that we have no conflicts of interest.

\section{Acknowledgments}

This study received funding from the National Institutes of Science and Technology Programme, Ministry of Science and Technology, and Council for Scientific and Technological Development Programme (CNPq; contract no. 5737862008-9), Brazil.

\section{References}

1 World Bank. Conditional cash transfer. A World Bank policy research report. Washington: World Bank, 2009.

2 Handa S, Davis B. The experience of conditional cash transfers in Latin America and the Caribbean. Development Policy Rev 2006; 24: 513-536.

3 Lindert K, Linder A, Hobbs J, Briere B. The nuts and bolts of Brazil's Bolsa Familia Program: implementing conditional cash transfers in a decentralized context. http://siteresources.worldbank. org/INTLACREGTOPLABSOCPRO/Resources/BRBolsaFamilia DiscussionPaper.pdf (accessed April 8, 2013)

4 Ministerio do Desenvolvimento Social e Combate a Fome. Matriz de Informação Social. http://aplicacoes.mds.gov.br/sagi/mi2007/ tabelas/mi_social.php (accessed April 8, 2013).

5 Ministério do Desenvolvimento Social. Bolsa Família. http://www. mds.gov.br/bolsafamilia/ (accessed April 8, 2013).

6 Ministério da Saúde. Manual de orientações sobre o Bolsa Família na Saúde. 2009. http://bvsms.saude.gov.br/bvs/publicacoes/manual orientacao_sobre_bolsa_familia.pdf (accessed April 8, 2013).

7 Ministério da Saúde. Departamento de Informática do SUS. DATASUS. http://www2.datasus.gov.br/datasus/index.php (accessed April 8, 2013).

8 Ministério da Saúde. Guia pratico do programa da Saude da Familia. Brasilia: Ministerio da Saude, 2001.

9 Victora CG, Aquino EM, do Carmo Leal M, Monteiro CA, Barros FC, Szwarcwald CL. Maternal and child health in Brazil: progress and challenges. Lancet 2011; 377: 1863-76.

10 UNICEF. Brazil, statistics. http://www.unicef.org/infobycountry/ brazil_statistics.html (accessed April 8, 2013).
11 Aquino R, Oliveira NF, Barreto ML. Impact of the Family Health Program on infant mortality in Brazilian municipalities. Am J Public Health 2009; 99: 87-93.

12 Rasella D, Aquino R, Barreto ML. Reducing childhood mortality from diarrhea and lower respiratory tract infections in Brazil. Pediatrics 2010; 126: e534-40.

13 Paes-Sousa R, Santos LM, Miazaki ÉS. Effects of a conditional cash transfer programme on child nutrition in Brazil. Bull World Health Organ 2011; 89: 496-503.

14 Paes-Sousa R, Quiroga J. Programas de transferência de renda e redução da pobreza e das desigualdades sociais no Brasil. Brazil: Ministerio da Saude, 2011.

15 Rasella D, Aquino R, Barreto ML. Impact of the Family Health Program on the quality of vital information and reduction of child unattended deaths in Brazil: an ecological longitudinal study. BMC Public Health 2010; 10: 380.

16 Andrade CLT, Szwarcwald CL. Sociospatial inequalities in the adequacy of Ministry of Health data on births and deaths at the municipal level in Brazil, 2000-02. Cad Saúde Publica 2007; 23: 1207-16 (in Portuguese).

17 WHO. The Global Burden of Disease: 2004 update. www.who.int healthinfo/global_burden_disease/2004_report_update/en/index html (accessed April 8, 2013).

18 IBGE. Instituto Brasileiro de Geografia e Estatistica. http://www. ibge.gov.br (accessed April 8, 2013).

19 Hilbe JM. Negative binomial regression. Cambridge, UK Cambridge University Press, 2007

20 Wooldridge JM. Introductory Econometrics, a modern approach, 3rd edn. Cinicinnati: South-Western College Publishers, 2005.

21 Shahidur RK, Koolwal GB, Samad HA. Handbook on impact evaluation: quantitative methods and practices. Washington DC: World Bank Publications, 2010.

22 Macinko J, de Oliveira VB, Turci MA, Guanais FC, Bonolo PF, Lima-Costa MF. The influence of primary care and hospital supply on ambulatory care-sensitive hospitalizations among adults in Brazil, 1999-2007. Am J Public Health 2011; 101: 1963-70.

23 Lagarde M, Haines A, Palmer N. The impact of conditional cash transfers on health outcomes and use of health services in low and middle income countries. Cochrane Database Syst Rev 2009; 4: CD008137.

24 Ranganathan M, Lagarde M. Promoting healthy behaviours and improving health outcomes in low and middle income countries: a review of the impact of conditional cash transfer programmes. Prev Med 2012; 55 (suppl): S95-105.

25 Gaarder MM, Glassmanb A, Todd JE. Conditional cash transfers and health: unpacking the causal chain. J Develop Effect 2010; 2: 6-50.

26 Barham T. A healthier start: The effect of conditional cash transfers on neonatal and infant mortality in rural Mexico. J Development Econ 2011; 94: 74-85.

27 Knaul FM, González-Pier E, Gómez-Dantés O, et al. The quest for universal health coverage: achieving social protection for all in Mexico. Lancet 2012; 380: 1259-79.

28 Ecob R, Smith GD. Income and health: what is the nature of the relationship? Soc Sci Med 1999; 48: 693-705.

29 Black RE, Allen LH, Bhutta ZA, et al, for the Maternal and Child Undernutrition Study Group. Maternal and child undernutrition: global and regional exposures and health consequences. Lancet 2008; 371: 243-60.

30 De Bem Lignani J, Sichieri R, Burlandy L, Salles-Costa R. Changes in food consumption among the Programa Bolsa Familia participant families in Brazil. Public Health Nutr 2011; 14: 785-92.

31 Wagstaff A, Bustreo F, Bryce J, Claeson M, for the WHO-World Bank Child Health and Poverty Working Group. Child health: reaching the poor. Am J Public Health 2004; 94: 726-36.

32 Gwatkin D, Habicht JP, Bryce J, et al, for the Multi-Country Evaluation of IMCI Study Group. Reducing child mortality: can public health deliver? Lancet 2003; 362: 159-64.

33 Jones G, Steketee RW, Black RE, Bhutta ZA, Morris SS, for the Bellagio Child Survival Study Group. How many child deaths can we prevent this year? Lancet 2003; 362: 65-71.

34 Macinko J, Lima Costa MF. Access to, use of and satisfaction with health services among adults enrolled in Brazil's Family Health Strategy: evidence from the 2008 National Household Survey. Trop Med Int Health 2012; 17: 36-42. 